\title{
Audit of an ophthalmology waiting list
}

\author{
H F Thomas, R H J Darvell
}

\begin{abstract}
The hospital case notes of $209(98 \%)$ of the 213 patients placed on an adult ophthalmic surgical waiting list between mid 1984 and mid 1985 were reviewed. Information on referral sources, previous eye surgery, outpatient visits, and treatment up to the end of 1987 was recorded. The vital status of patients up to the end of 1988 was also ascertained. Waiting list patients (123 women, 86 men) were elderly (73\% over 65 years) and most $(70 \%)$ were listed for cataract surgery. By the end of 1987 (30-42 months after waiting list entry) $64 \%$ of all patients (and $56 \%$ of cataract patients) had received surgery under the care of the health authority. The remainder had either died $(12 \%)$, received surgery elsewhere $(7 \%)$, were still on the waiting list (7\%), no longer wanted or were unfit for surgery $(6 \%)$, or had left the district (4\%). By the end of 1988 (42-54 months after waiting list entry) $28 \%$ of the original waiting list population had died.
\end{abstract}

Medical audit has been defined as the systematic review by doctors of their own work ${ }^{1}$ and as the detailed retrospective review and evaluation of selected medical records by qualified professional staff. ${ }^{2}$ The present government has a commitment to establish medical audit in British hospitals, ${ }^{3}$ and the College of Ophthalmologists and the Royal College of Surgeons support this objective. This study is an attempt to audit an ophthalmic waiting list by examining background information about adult patients on a waiting list, some of the processes related to being placed on the list, outcome in terms of receiving surgery, and total mortality up to 54 months after being placed on the list. The study was also intended to provide some practical lessons in undertaking audit.

\section{Materials and methods}

The hospital case notes of 209 (98\%) adults placed on the Thanet ophthalmic waiting list between 30 June 1984 and 31 July 1985 were reviewed and a number of facts abstracted and tabulated. Four sets of notes were not located. A list of patients with their dates of birth was sent to the local Registrar of Births and Deaths, and

Canterbury and Thanet Health Authority District Headquarters, Ramsgate H F Thomas

Kent and Canterbury Hospital, Canterbury R H J Darvell

Correspondence to: Dr H F Thomas, Department of Public Health and Epidemiology, Odstock Hospital, Salisbury, Wilts SP2 8BJ.

Accepted for publication 2 August 1990 this department identified patients deceased locally up to the end of 1988 .

\section{Results}

Table 1 shows the age and sex structure of the waiting list. Patients were mainly women (59\%) and elderly, with $73 \%$ over 65 years and $47 \%$ over 75 years. Five patients were placed on the list twice for different procedures during the study period.
Table 2 shows the operations specified for waiting list patients. Cataract surgery was the commonest procedure (70\%), with lacrimal, lid and glaucoma surgery together accounting for only 34 (17\%) procedures.

SOURCES OF REFERRAL

Information on the sources of referral for the condition leading to entry on the waiting list was available for $189(90 \%)$ patients. Most patients (92) had only been seen by their general practitioner, while 79 were referred by their general practitioner following a visit to an optician. Internal hospital referrals from diabetic and other clinics provided 18 patients.

\section{PREVIOUS OPHTHALMIC TREATMENT}

Review of previous ophthalmic notes showed that $32(15 \%)$ patients had first seen local hospital ophthalmologists 10 or more years before the present study period (1984-5), and 75 (36\%) had been first seen five or more years before entry to the waiting list. Eighty seven patients $(42 \%)$ had received previous ophthalmic surgery in the district for conditions such as cataract (39), glaucoma (10), lacrimal problems (8), squint (6), and retinal detachment (5). Thirty-two (22\%) of the cataract operations specified on the waiting list were to second eyes.

OUTPATIENT VISITS BEFORE WAITING LIST ENTRY Table 3 shows the number of outpatient visits people made before being placed on the waiting list. About a fifth of patients ( $22 \%)$ were entered on their first visit, half were listed within five visits, while a quarter ( $28 \%$ ) made 10 or more visits before going on the list.

Table 1 Age and sex of waiting list patients

\begin{tabular}{llllllc}
\hline \multicolumn{7}{c}{ Age group (years) } \\
\hline Sex & $15-44$ & $45-64$ & $65-74$ & $75-84$ & $85+$ & All ages \\
\hline Male & 11 & 18 & 28 & 24 & 5 & 86 \\
Female & 4 & 24 & 25 & 61 & 9 & 123 \\
Total & 15 & 42 & 53 & 85 & 14 & 209 \\
\hline
\end{tabular}

Five patients are included twice (see text).

Table 2 Operations specified for 209 waiting list patients

\begin{tabular}{lcc}
\hline Operation & Number & Percentage \\
\hline Cataract extraction & 147 & 70 \\
Lacrimal surgery & 18 & 9 \\
Lid surgery & 8 & 4 \\
Glaucoma surgery & 8 & 4 \\
Squint surgery & 7 & 3 \\
Retinal surgery & 5 & 2 \\
Skin grafting & 4 & 2 \\
Pterygium removal & 3 & 1 \\
Vitrectomy & 2 & 1 \\
Other procedures & 7 & 3 \\
\hline
\end{tabular}


OUTCOME FOR WAITING LIST PATIENTS

Table 4 shows what had happened to patients by the end of 1987 (30-42 months from waiting list entry). Overall $133(64 \%)$ patients had received surgery in the district eye unit, with a lower percentage $(82: 56 \%)$ of cataract patients being treated at the unit. For the 82 patients who received cataract surgery the waiting times after being placed on the list were less than a year for $22(27 \%)$, between one and two years for 14 $(17 \%)$, and between two and three years for 46 $(56 \%)$. Fourteen other cataract patients had surgery elsewhere either privately (9), at Moorfields (4), or in another district (1).

Patients did not receive surgery for a variety of reasons, the main one (12\%) being death before being called for surgery. Of the 27 patients who died while on the waiting list during the 42 month follow-up period, seven died within the first year, 15 after one to two years, and five after two years. Review of local death registers up to the end of 1988 (42-54 months from waiting list entry) identified 58 deaths (28\%) in the study population. None was linked to operative complications. The deceased were elderly on entry to the waiting list (mean age: males 77 years, females 78 years), and deaths were equally distributed among the sexes (28\% males, $29 \%$ females).

Thirty-six (27\%) of the 133 patients who received surgery under the district health authority had their operation postponed once (29), twice (4), and even three times (3). Hospital factors, such as no anaesthetist or no bed accounted for 17 postponements, with patient factors, such as ill health, contributing to the remainder. The case notes of patients were reviewed mainly during the first half of 1988 , by which time $34(17 \%)$ of the study population had either been listed for or undergone further ophthalmic surgery in the district.

Table 3 Number of outpatient visits before being placed on waiting list

\begin{tabular}{llll}
\hline $\begin{array}{l}\text { Number of } \\
\text { visits }\end{array}$ & $\begin{array}{l}\text { Number of } \\
\text { patients }\end{array}$ & Percentage & $\begin{array}{l}\text { Cumulative \% } \\
\text { (rounded up) }\end{array}$ \\
\hline 1 & 44 & $21 \cdot 7$ & 22 \\
2 & 16 & $7 \cdot 9$ & 30 \\
3 & 18 & $8 \cdot 9$ & 39 \\
4 & 8 & $3 \cdot 9$ & 42 \\
5 & 16 & $7 \cdot 9$ & 50 \\
6 & 17 & $8 \cdot 4$ & 59 \\
7 & 11 & $5 \cdot 4$ & 64 \\
8 & 9 & $4 \cdot 4$ & 69 \\
9 & 9 & $4 \cdot 4$ & 73 \\
10 & 3 & $1 \cdot 5$ & 74 \\
$11-14$ & 13 & $6 \cdot 4$ & 81 \\
$15-19$ & 9 & $4 \cdot 4$ & 85 \\
$20-24$ & 12 & 5.9 & 91 \\
$25-30$ & 3 & 1.5 & 93 \\
$31+$ & 15 & $7 \cdot 4$ & 100 \\
\hline
\end{tabular}

$\mathrm{n}=203$ (information not available for six patients).

Table 4 Outcome for waiting list patients up to the end of 1987

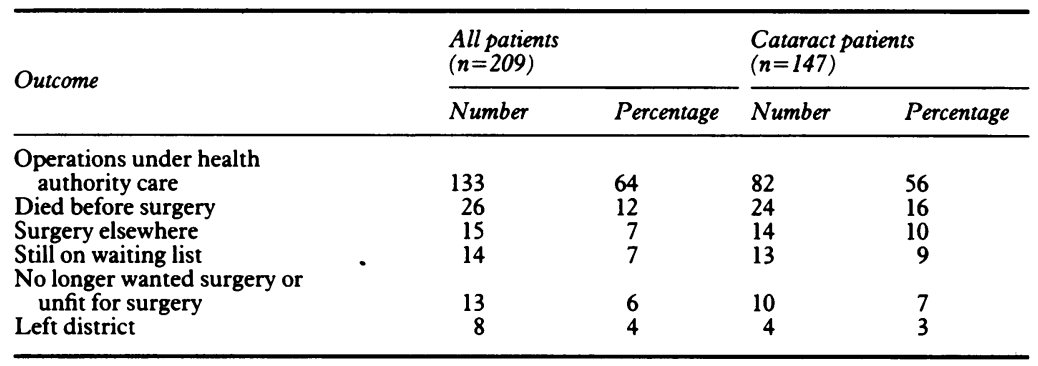

\section{Discussion}

This project was made possible because a medical records officer kept a complete record of adult patients entered in a waiting list over the previous four years. The waiting lists for children, minor operations, and laser treatment were incomplete for the study period, and these patients were therefore excluded from the study. In many districts waiting lists are kept as a card index and cannot be reconstructed for past years, thus making this type of study impossible.

Obtaining the patients' case notes was hindered by staffing shortages in the medical records department, a not uncommon situation in many British hospitals. The District Department of Public Health Medicine provided clerical help to obtain medical records and to process the data. Reviewing hospital notes and searching for entries relevant to a single specialty is time consuming even when carried out by medical or nursing staff. It took between 3 and 20 minutes to review and abstract information from individual case notes.

The age of the waiting list population reflects the high proportion of elderly people resident in the district ( $22 \%$ over 65 years compared with $15 \%$ in England and Wales). General practitioners rather than opticians appear to be the main source of outpatient referrals, a finding consistent with those of other studies. ${ }^{4}$ Almost half $(42 \%)$ of the waiting list group had previously undergone ophthalmic surgery and at least $17 \%$ of the group were listed to receive or had received further eye surgery after the operation specified in the study period. This illustrates the continuing demand for eye surgery by old as well as new patients.

Only a small proportion of eye patients are discharged from eye clinics, and most, particularly those with glaucoma or retinal problems, are kept under long term outpatient review. This maintains constant pressure on outpatient departments. Most of the case notes reviewed recorded at least one 'clinics cut down' when patients' appointments had had to be postponed to accommodate more urgent cases. Long term follow-up makes it difficult to isolate separate medical episodes when reviewing notes. The criterion for new cases was a new general practitioner's letter or casualty attendance. General practitioners' letters seeking to expedite treatment for patients already under follow-up were excluded. Most of the patients who made more than 10 outpatient visits before entry to the waiting list had been on long term medical treatment, for example for glaucoma, or had received surgery to one eye and were being followed up to ensure that their second eye received appropriate treatment, for example for cataract. Cataract surgery on the second eye (that is, one eye already having undergone cataract removal) is standard policy in the district despite the heavy workload. We understand that in some districts few second eyes are done in elderly patients. This may keep waiting lists down but does not perhaps offer the optimum standard of care.

The finding that only two-thirds of all waiting list patients and only just over half of the cataract patients reach surgery under district health 
authority care is disappointing. Surgical operation rates compare favourably with those of other districts, but the present surgeons inherited long waiting lists, and the aging population has meant that demand for eye surgery has continued to grow. To tackle the long waiting list an Operation Cataract scheme was undertaken in 1989. ${ }^{5}$ Other measures to reduce surgical waiting times are also being taken. Official statistics ${ }^{6}$ for 1988 show that $36 \%$ of the district's ophthalmic patients were waiting over 12 months for surgery. The Operation Cataract scheme has improved this situation, and average waiting times are now about six to nine months. In England and Wales $17 \%$ of the 66000 patients waiting for ophthalmic surgery had waited for over one year since entry to the waiting list. ${ }^{6} \mathrm{~A}$ quarter of health districts in England and Wales offering ophthalmic surgery have a higher proportion of patients waiting over 12 months for eye surgery than in Canterbury and Thanet. The situation in our authority is therefore not uncommon. This delay to surgery is regrettable in view of the benefits that surgery can bring and also the limited life expectancy of the elderly patients. Over a quarter of the study population were dead within four years of going on the waiting list. This figure may be an underestimate, as only local death records were searched, and some patients may have moved away and died.

This study, by examining a defined population prospectively, gives a better insight into the dynamics of a waiting list than does the review of cross-sectional routine statistics which do not follow up the fate of individual patients.

We gratefully acknowledge the help of medical records officers, Thanet District General Hospital, Mr Newman, Registrar of Births and Deaths, Thanet District, Professor L Opit, Centre for Health Service Studies, University of Kent, and Mr I Dawson, who provided computing assistance.

1 Shaw CD. Acceptability of audit. Br Med F 1980; 281: 1443-5.

2 Rogers PG, Discursive dictionary of health care - subcommittee on health and environment. Washington: US Government Printing Office, 1976

3 Department of Health Working Party No 6. Medical audit. London: HMSO, 1989.

4 Harrison RJ, Wild JM, Hobley AJ. Referral patterns to an ophthalmic outpatient clinic by general practitioners and ophthalmic opticians and the role of these professionals in screening for ocular disease. Br Med F 1988; 297: 1162-7.

5 Thomas HF, Darvell RHJ, Hicks C. 'Operation cataract', a means of reducing waiting lists for cataract operations. BrMed F 1989; 299: 961-3.

6 College of Health. Guide to hospital waiting lists. London: College of Health, 1989 .

\section{FIFTY YEARS AGO}

\section{Annotation: 'My eyes are dim'}

The fact that one of the marching songs of the British army in the current war begins 'My eyes are dim, I cannot see,' is of interest as we believe it to be the first instance of an ophthalmic sentiment being made use of in this connexion. In the Great War 'Tipperary' held the field; in the present 'Roll out the barrel' bids fair to be as popular. The Marseillaise must, we think, be the most famous marching song in history, though 'John Brown's body' runs it close. The fact that Uncle Toby was addicted to whistling half-a-dozen bars of 'Lillibullero' leads one to the conclusion that those British soldiers, who swore so terribly in Flanders, got rid of some of their superfluous energy with this tune. The French are said to have used 'Malbrouk s'en va-t-en guerre' during the Revolution. Brewer, in his Dictionary of Phrase and Fable, says that this song dates from the Crusades and has nothing to do with the Duke of Marlborough; and it is now chiefly memorable for Thackeray's ridiculous drawing of Duchess Sarah taking leave of her husband. Was Kipling's 'Absent minded beggar' much used in the South African war of 1899-1902? Our Scottish readers, if any chance upon this note, will doubtless hum 'Hey Johnny Cope'; and it is common knowledge that Cromwell's Ironsides went into action singing psalms. Napoleon gave orders that French troops in the Peninsula should be supplied with at least three different songs, and for all we know to the contrary William the Conqueror may have countenanced a marching song at Hastings. Marching songs are probably as old as armies themselves.

We have even heard of an example of ophthalmic humour in the eye ward of one of the London Hospitals where the children greeted the dawn with the roundelay 'Dancing with tears in my eyes.'

BrJ Ophthalmol 1940: 24: 360. 